\title{
A Non-woven Path: Electrospun Poly(lactic acid) Scaffolds for Kidney Tissue Engineering
}

\author{
Todd P. Burton ${ }^{1}\left[\begin{array}{c}\text { [D } \\ \text { Anthony Callanan }\end{array}\right.$
}

Received: 7 September 2017/Revised: 15 November 2017/Accepted: 3 December 2017/Published online: 14 February 2018

(C) The Author(s) 2017. This article is an open access publication

\begin{abstract}
Chronic kidney disease is a major global health problem affecting millions of people; kidney tissue engineering provides an opportunity to better understand this disease, and has the capacity to provide a cure. Two-dimensional cell culture and decellularised tissue have been the main focus of this research thus far, but despite promising results these methods are not without their shortcomings. Polymer fabrication techniques such as electrospinning have the potential to provide a non-woven path for kidney tissue engineering. In this experiment we isolated rat primary kidney cells which were seeded on electrospun poly(lactic acid) scaffolds. Our results showed that the scaffolds were capable of sustaining a multipopulation of kidney cells, determined by the presence of: aquaporin-1 (proximal tubules), aquaporin-2 (collecting ducts), synaptopodin (glomerular epithelia) and von Willebrand factor (glomerular endothelia cells), viability of cells appeared to be unaffected by fibre diameter. The ability of electrospun polymer scaffold to act as a conveyor for kidney cells makes them an ideal candidate within kidney tissue engineering; the non-woven path provides benefits over decellularised tissue by offering a high morphological control as well as providing superior mechanical properties with degradation over a tuneable time frame.
\end{abstract}

Keywords Kidney tissue engineering $\cdot$ Scaffold architecture $\cdot$ Electrospinning $\cdot$ Primary cells $\cdot$ Renal

\section{Introduction}

Chronic kidney disease (CKD) is a major worldwide health problem which attributes to $1.5 \%$ of deaths worldwide [1]. Current treatment involves dialysis and eventual transplantation; dialysis is a costly technique which constrains day to day life [2]. In 2016 there were 5275 people on the transplant list in the UK alone [3], this places huge stresses on health care providers as demand outstrips supply. Recent strategies to overcome these shortcomings in transplants are mainly focused on social policy with a new system of presumed consent being proposed [4]. Additional

Anthony Callanan

anthony.callanan@ed.ac.uk

1 Institute of Bioengineering, School of Engineering, The University of Edinburgh, Faraday Building, The King's Buildings, Mayfield Road, Edinburgh EH9 3JL, UK to this there are new avenues and endeavours in bioartificial kidney devices acting as miniaturised implantable dialysis devices which are showing great promise [5]. Furthermore, kidney tissue engineering is one avenue that could provide a better basis for treatment and understanding of CKD and has the unique potential to help meet the ever-growing demand for organs.

Initial success in kidney tissue engineering have shown potential as a testing platform for nephrotoxicity [6]. Current research has focused on simple microfluidic [7-11] and co-culture $[12,13]$ models representing structures such as the proximal tubules $[7-9,11]$ or glomerulus $[10,12,13]$; other approaches have included the use of embryonic or induced pluripotent cells cultured on tissue culture plastic creating immature kidney organoids [14-16]. A key element missing from these approaches is a 3D scaffold capable of providing mechanical strength, architectural cues and structure. 
It is well documented that a 3D structure affects many different cell types [17-20] and could quite possibly be a crucial element of kidney tissue engineering. Decellularised tissue is currently the predominant vehicle for 3D kidney cell culture with impressive advances made [21-24]. This involves flushing detergent through renal tissue to wash out cells and DNA. This acellular extracellular matrix $(E C M)$ is then recellularized and in some cases has been documented to produce rudimentary urine [25]. However, the decellularisation of tissue is not a simple process and the material left behind is often poorly characterised and mechanically weak [21, 26, 27], added to this the formidable task of recellularization [28] yielding enough uncertainty that other avenues should be pursued alongside.

Biomaterials such as polymer scaffolds have been investigated for kidney tissue engineering in a limited capacity, predominantly through investigation into hollow fibre bioreactors [29] but also as a conduit for renal segments [30]. Synthetic polymers, such as PLGA, have also been combined with natural ECM and have shown to enhance biocompatibility and reduce hydrophobicity of scaffolds compared to PLGA alone [31]. The paucity of research in polymer scaffold for kidney tissue engineering leave many avenues unexplored.

Electrospinning is a technique that has been utilised in many areas of tissue engineering to yield non-woven fibres resembling the ECM [32]. The technique produces consistent scaffold properties that can be precise when environmental parameters are finely controlled, including humidity, temperature, polymer concentrations, voltagepower, grounding and flow rate [33]. Morphologies of electrospun scaffolds can also be controlled and can affect how cells behave, larger fibres result in greater cell integration, nanofibers give a better representation of ECM and aligned fibres can induce linear orientation of cells [34-36]. Techniques such as cryogenic electrospinning have also demonstrated to increase the porosity of scaffolds allowing for greater cell integration [37]. In kidney tissue engineering electrospun collagen has been utilised to model the glomerular capillary wall, with evidence of cell-cell communication [13]. Electrospun polycaprolactone has previously been used for culturing epithelial and endothelial cell and shown to support cell life. Cells were seen to migrate into scaffolds, an outcome which is highly desirable for a multi-cell population required to create an organoid [38].

We have previously shown the ability of electrospun scaffolds to support a kidney cell line [39]. Here, for the first time to the authors knowledge, we study the growth of a multipopulation of rat primary kidney cells on poly(lactic acid) scaffolds of differing morphologies. With there being a distinct lack of research into polymer scaffold for kidney cells, here we show their intrinsic potential as a microenvironment that can maintain multiple cell phenotypic characteristics.

\section{Materials and methods}

\subsection{Electrospinning}

Poly(lactic acid) (PLA) (Goodfellow, UK) was spun at 3 different percentage weight by volume solutions in 1,1,1,3,3,3-hexafluoro-2-isopropanol (HFIP) (Manchester Organics, UK). Small fibres were created from a $10 \% \mathrm{w} / \mathrm{v}$ solution at $+17,-2 \mathrm{kV}$ with a flow rate of $0.5 \mathrm{ml} / \mathrm{h}$ at a needle to mandrel distance of $140 \mathrm{~mm}$, needle bore of $0.4 \mathrm{~mm}$. Medium fibres were created from an $18 \% \mathrm{w} / \mathrm{v}$ solution at $+15,-4 \mathrm{kV}$ with a flow rate of $4 \mathrm{ml} / \mathrm{h}$ at a needle to mandrel distance of $200 \mathrm{~mm}$, needle bore of $0.8 \mathrm{~mm}$. Large fibres were created from a $22 \% \mathrm{w} / \mathrm{v}$ solution at $+16,-4 \mathrm{kV}$ with a flow rate of $4 \mathrm{ml} / \mathrm{h}$ at a needle to mandrel distance of $23 \mathrm{~mm}$, needle bore $0.8 \mathrm{~mm}$. Cryogenic fibres were created using the same parameters but with a mandrel filled with dry ice $\left(-78.5^{\circ} \mathrm{C}\right)$, topping up with dry ice each hour. The low temperature causes ice crystal deposition on the mandrel, increasing the porosity of scaffolds. After spinning the mandrel is freeze dried for $24 \mathrm{~h}$, leaving behind a cryogenically modified scaffold. All fibres were spun at $250 \mathrm{rpm}$ on to a mandrel covered in aluminium foil with $16 \mathrm{ml}$ of solution used for each scaffold. Electrospun sheets were dried in a fume hood for $24 \mathrm{~h}$ to remove residual solvent and cut into $10 \mathrm{~mm}$ disks ready for cell seeding.

\subsection{Mechanical testing}

Mechanical testing was performed using an Instron 3367 (Instron, UK) tensile testing machine. A gauge length of $20 \mathrm{~mm}$ and width of $5 \mathrm{~mm}$ was used for test pieces and thickness was measured using a digital micrometre. Samples were strained at $50 \%$ strain per minute with ultimate tensile strength and incremental Young's modulus (between 0 and 5\% strain in 1\% intervals) calculated from an $\mathrm{N} \geq 5$ independent replicates, as previously described [40].

Estimated porosity was calculated by measuring the density of the scaffold and dividing it by the known density of PLA, as in the equation below:

Porosity $=\left(1-\frac{\text { Density of Scaffold }}{\text { Density of Polymer }}\right) \times 100$ 


\subsection{Scanning electron microscopy}

Fibres were coated using an Emscope SC500A splutter coater using gold-palladium (60:40). A Hitachi S4700 fuelled emission scanning electron microscope (SEM) (Hitachi) with a $5 \mathrm{kV}$ accelerating voltage and a working distance of $12 \mathrm{~mm}$ was used to image scaffolds.

\subsection{Primary rat kidney isolation}

Kidneys were taken from a 4-week-old female SpragueDawley rat and washed in Krebs-Ringer bicarbonate buffer supplemented with $1 \%$ antibiotic/antimycotic (anti/anti). The renal capsule and adjacent connective tissue were removed, and kidneys washed before placing in a falcon tube containing Krebs-Ringer and anti/anti. Kidneys were transferred to a cell culture hood and minced in a petri-dish using a scalpel. Minced tissue was incubated in collagenase from clostricium histolyticum (Sigma-Aldrich, UK) at a concentration of $0.625 \mathrm{mg} / \mathrm{ml}$ for $30 \mathrm{~min}$ at $37{ }^{\circ} \mathrm{C}$, 2 kidneys per $12.5 \mathrm{ml}$. Following, the solution was filtered through a $70 \mu \mathrm{m}$ cell strainer and neutralised with Dulbecco's Modified Eagle's Medium (DMEM) supplemented with $1 \%$ anti/anti and $10 \%$ foetal bovine serum (FBS). The solution was centrifuged at $500 \mathrm{~g}$ for $5 \mathrm{~min}$ and the supernatant discarded. Cells were resuspended in a 1:1 ratio of DMEM and keratinocyte serum-free media (KSFM) supplemented with $25 \mathrm{mg}$ bovine pituitary extract and $2.5 \mu \mathrm{g}$ epidermal growth factor, 5\% FBS and 1\% anti/ anti. Cells were plated with 2 kidneys in 5 T175 flasks and cultured for $24 \mathrm{~h}$ before washing with PBS and replenishing media. Protocol adapted from $\mathrm{He}$ et al. [21] and Joraku et al. [41].

\subsection{Cell seeding}

Scaffolds were sterilised in 2-propanol for $30 \mathrm{~min}$ before washing 3 times in phosphate buffered saline (PBS). Trypsin-EDTA $0.05 \%$ was used to lift cells from culture flasks, neutralised in cell culture media and centrifuged at $500 \mathrm{~g}$ for $5 \mathrm{~min}$. In 12 well suspension plates, 400,000 cells (p1) were seeded to each scaffold in $50 \mu \mathrm{l}$ media and left to attach for an hour before adding an additional $400 \mu \mathrm{l}$ media. Cultures were incubated at $37{ }^{\circ} \mathrm{C}$ in $5 \% \mathrm{CO}_{2}$ for 3 and 7 days and media was changed every 2 days.

\subsection{Cell viability}

A CellTitre-Blue ${ }^{\circledR}$ assay (Promega, UK) was used to evaluate cell viability. Scaffolds were placed in a new 48 well suspension plate and washed 3 times in PBS, $480 \mu$ of stock solution (5:1, media/assay) was added to each scaffold and incubated for $2 \mathrm{~h}$. Fluorescence was read using a microplate reader (Modulus II 9300-062, Turner Biosystems) at Ex $520 \mathrm{~nm}$ Em 580-640 nm, N = 4 independent replicates. A standard curve was used to estimate cell number.

\subsection{DNA quantification}

Scaffolds were washed 3 times in PBS and freeze dried for $24 \mathrm{~h}$. Each scaffold was incubated within an ultrasonic bath (6 litre Cavitek Digital, The Allendale Group, UK) in $300 \mu \mathrm{l}$ of a 2.5 units $/ \mathrm{ml}$ papain digest solution, $5 \mathrm{mM}$ cysteine HCL and $5 \mathrm{mM}$ EDTA in PBS (all reagents from Sigma Aldrich, UK) at $60^{\circ} \mathrm{C}$ for $24 \mathrm{~h}$ with periodic sonication. Total DNA content of the samples was calculated using a Quant-iT ${ }^{\mathrm{TM}}$ PicoGreen ${ }^{\circledR}$ assay kit (ThermoFisher, UK) as per the manufacturers' instructions. Fluorescence was read using a microplate reader at Ex $490 \mathrm{~nm}$ Em 510-570 nm, $\mathrm{N}=4$ independent replicates.

\subsection{Immunohistochemistry imaging}

Scaffold were washed 3 times in PBS and fixed in a 3.7\% (v/v) solution of formalin and PBS for 10 min, followed by 3 additional washes. Permeabilization was performed using a $0.05 \%$ TWEEN in a $10 \mathrm{mM}$ Tris and $1 \mathrm{mM}$ MEDTA solution, scaffolds were incubated in $300 \mu \mathrm{l}$ for $1 \mathrm{~h}$ before washing 3 times.

Scaffolds were dehydrated in 2-propanol solutions graduating from 30 to $100 \%$ for $10 \mathrm{~min}$ in each. Scaffolds were then left in a solution of 2-propanol and polyester wax (1:1) at $50{ }^{\circ} \mathrm{C}$ overnight. Next, scaffolds were placed in polyester wax for $3 \mathrm{~h}$ and then fresh wax overnight at $50{ }^{\circ} \mathrm{C}$. Scaffold were halved and blocked for sectioning into $35 \mu \mathrm{m}$ slices.

Cell were stained for DNA using $0.1 \mathrm{mg} / \mathrm{ml} \mathrm{4}$,6-diamidino-2-phenylindole (DAPI) (Sigma-Aldrich, UK) in PBS for $10 \mathrm{~min}$. IHC was performed to establish the presence of key cell types including, primary antibodies aquaporin-1, aquaporin-2 and synaptopodin (Stratech, UK) were used at a $1 \mu \mathrm{g} / \mathrm{ml}$ dilution, von Willebrand factor (Abcam, UK) was used at $2 \mu \mathrm{g} / \mathrm{ml}$ (Fig. 1), and scaffold were incubated overnight in $10 \mu \mathrm{l}$, no-primary controls were used. Alexa Fluor 488 anti-rabbit IgG (ThermoFisher, UK) was used as a secondary antibody and left to incubate for $1 \mathrm{~h}$ before performing 3 washes, $5 \mathrm{~min}$ each. Imaging was done using a Zeiss Axio Imager fluorescence microscope.

\subsection{Statistical analysis}

Data was tested using Levene's test for equal variance before statistical analysis was performed in order to select appropriate tests. Electrospun fibre diameters were 
analysed using a one-way ANOVA with post hoc GamesHowel test. CellTitre blue and mechanical data was analysed using a one-way ANOVA with post hoc Tukey pairwise comparison; as data had a slight positive skew it was transformed by natural log giving a more normal distribution. Data on electrospun fibres is presented as mean \pm standard deviation, all graphs are presented as mean $\pm 95 \%$ confidence interval, circles on graphs denote individual data points.

\section{Results}

\subsection{Electrospun fibres}

Non-woven fibres were created by electrospinning, it is clear that the variation in spinning parameters produced scaffolds of significantly different fibre diameters, $\mathrm{F}(3,87)=2274, p=0$ (Fig. 1). Discrepancies were found between cryogenic and large fibre diameters, despite spinning using the same parameters, which is as a result of natural variation between spinning sessions and colder spinning environment. Cryogenic electrospinning produced a scaffold 5 times thicker than spinning with traditional methods, this rise in thickness dramatically increases the porosity from $82.5 \%$ for large fibres spun using the same parameters to $97 \%$, but it does come at the cost of mechanical strength, Table 1.

The Young's modulus at $0-5 \%$ strain was analysed by one-way ANOVA, this analysis showed a significant difference between scaffolds $\mathrm{F}(3,21)=103.32, \quad p=0$, Table 1. Post hoc analysis using Tukey test showed that all scaffolds at 0-5\% strain, except medium compared to large fibres, were significantly different to each other, $p<0.001$.
Fig. 1 A diagram of the kidney showing the structure of kidney including the nephron and glomerulus, highlighting the location of key cell types, representative IHC images are taken from large scaffold at 7 days, scale bar is $100 \mu \mathrm{m}$

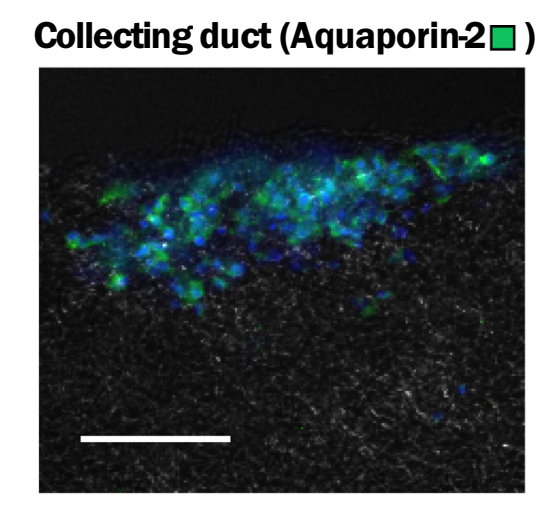

\section{Proximal tubules (Aquaporin-1 $\square$ )}
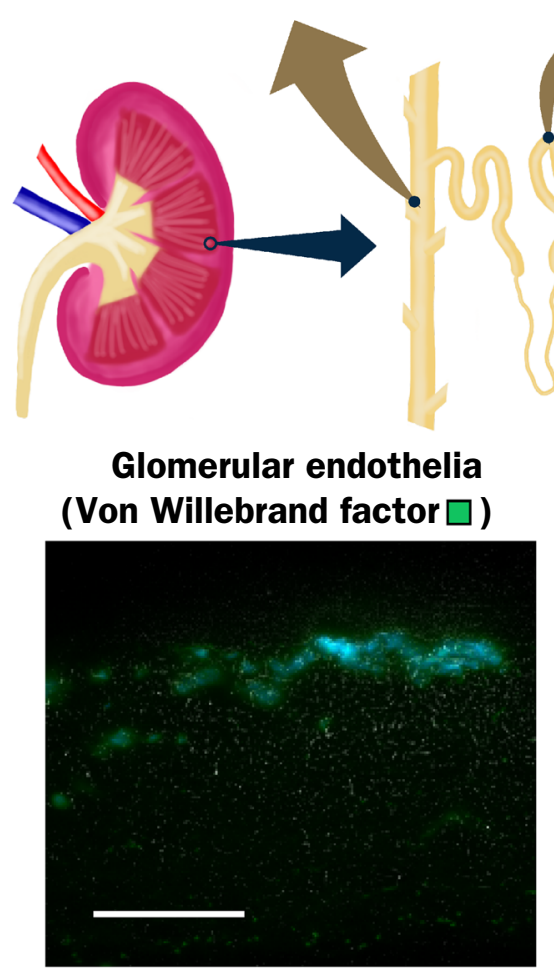

\section{Glomerular epithelia (Synaptopodin $\square$ )}

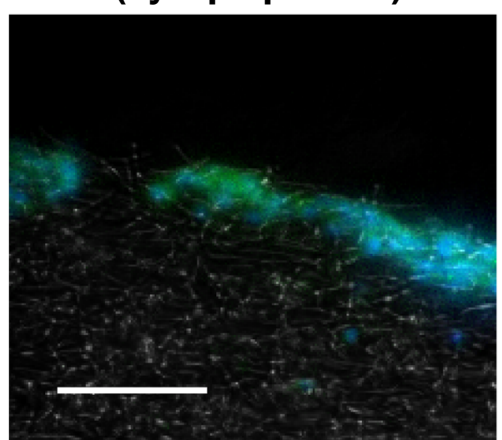


A similar trend follows with analysis of ultimate tensile strength, $\mathrm{F}(3,21)=133.31, \quad p=0$. Post-hoc analysis shows all scaffold are significantly different from each other except large and medium scaffolds, $p<0.05$. Notably, randomly spun scaffolds reach a peak Young's modulus at $2-3 \%$ strain whereas cryogenic spinning increases the percentage strain at which Young's modulus is highest to $3-4 \%$ strain.

\subsection{Cell viability and DNA quantification}

CellTitre Blue ${ }^{\circledR}$, which was used to determine cell viability, showed that cells did have a preference for a larger fibre diameter however these differences were not significant, the same applies to the number of viable cells from 3 to 7 days, $\mathrm{F}(7,24)=2.05, p=0.090$. However, when compared to cells grown on tissue culture plastic there were significantly more cell present within the 12 well plate control $\mathrm{F}(9,30)=18.23, p=0$, with post hoc analysis showing significantly more cells on tissue culture plastic than all scaffolds, Fig. 2.

Analysis of DNA quantification, determined by PicoGreen assay, using a one-way ANOVA showed a significant difference between groups, $\mathrm{F}(7,23)=4.79$, $p=0.002$. Post-hoc Tukey test highlighted that cryogenic scaffolds at day 3 was significantly different from all groups except cryogenic at day 7 and medium at day 3 , no other significant differences were seen. DNA quantification validates the fact that the number of cells is does not increase from 3 to 7 days, Fig. 3.

\subsection{Immunohistochemistry}

Immunohistochemistry (IHC) showed the presence of key signatures of several cell types: aquaporin 1 and 2 showed the presence of tubular cells, synaptopodin highlights glomerular epithelial cells and von Willebrand factor indicates glomerular endothelial cells. As seen in Fig. 4, these key markers are seen on all scaffold types, demonstrating the presence of a multi-population of cells. The sectioned scaffold show that cells were seen throughout cryogenic scaffolds, but less cell penetration was present on all other fibres types.

\section{Discussion}

Emphasis so far in kidney tissue engineering has been on 2D cell culture, which has shown considerable progression in recent years $[15,42,43]$. However, cells within the Kidney do not exist within the two dimensional axis of cell culture plastic, with greater amounts of research underlining the importance of a 3D structure [17, 44]. 3D kidney tissue engineering has focused on the use of decellularised tissue with promising results $[25,45]$; this method is not without its shortcomings, with issues surrounding decontamination [46] and a lack of a standardized approach to decellularisation leading to a variation between scaffolds [21, 26, 27]. Decellularised tissue brings favourable physical and chemical characteristics to help support cells and control physiology [47], but as cell produce their own ECM a synthetic scaffold can provide an excellent foundation to build upon [48, 49]. Polymer scaffolds offer many benefits over decellularised tissue as their manufacture can be highly controlled, as well as providing superior mechanical properties with degradation over a tuneable time frame $[31,33,50]$.

Our electrospun fibres demonstrate the control with which polymer scaffold are fabricated having a standard deviation in fibre diameter and Young's modulus (0-5\% strain) of less than $20 \%$ in all cases, Table 1 . The increase in porosity of $97.3 \%$ gained from cryogenic electrospinning, demonstrated in the dramatic increase in thickness of the scaffold spun under the same conditions as large fibres,

Table 1 Mechanical properties and physical properties of PLA scaffolds

\begin{tabular}{lccccc}
\hline Average & Strain & Small & Medium & Cryogenic & Large \\
\hline Fibre diameter, $\mu \mathrm{m}$ & - & $0.88 \pm 0.16$ & $2.46 \pm 0.43$ & $3.71 \pm 0.36$ & $3.30 \pm 0.17$ \\
Scaffold thickness, $\mu \mathrm{m}$ & - & $193 \pm 5.16$ & $270 \pm 8.63$ & $1375 \pm 160$ & $218 \pm 13.0$ \\
Porosity, \% & - & 86.9 & 82.8 & 97.3 & 82.5 \\
Young's modulus at \% Strain, MPa & $0-1 \%$ & $2.84 \pm 1.41$ & $5.78 \pm 1.51$ & $0.57 \pm 0.15$ & $7.15 \pm 1.97$ \\
& $1-2 \%$ & $6.53 \pm 0.85$ & $6.40 \pm 1.49$ & $0.72 \pm 0.16$ & $6.61 \pm 0.81$ \\
& $2-3 \%$ & $5.34 \pm 0.91$ & $9.13 \pm 1.12$ & $1.13 \pm 0.30$ & $8.69 \pm 1.48$ \\
& $3-4 \%$ & $4.76 \pm 0.54$ & $7.48 \pm 0.94$ & $1.31 \pm 0.21$ & $6.87 \pm 1.62$ \\
& $4-5 \%$ & $2.84 \pm 0.67$ & $4.22 \pm 0.62$ & $0.81 \pm 0.14$ & $3.59 \pm 1.13$ \\
Ultimate tensile strength, MPa & $0-5 \%$ & $5.05 \pm 0.52$ & $7.31 \pm 0.84$ & $1.01 \pm 0.20$ & $7.14 \pm 1.04$ \\
\hline
\end{tabular}




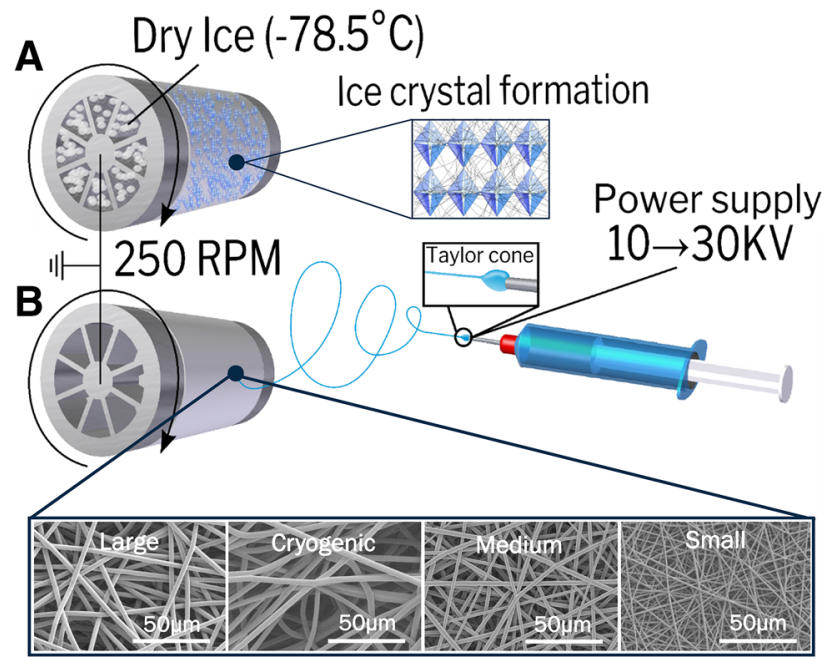

Fig. 2 Scaffolds were fabricated by electrospinning, where a high voltage is applied to a polymer solution, forming a Taylor cone, this is then accelerated towards a ground source. Fibre architecture was determined by spinning parameters; A cryogenic fibres, using ice crystal formation as a template for fibre deposition and $\mathbf{B}$ random fibres onto a slowly rotating mandrel. SEM images below demonstrate the difference in fibre diameter of the scaffolds, which were spun using the same solvent and polymer but different electrospinning parameters and percentage weight solutions

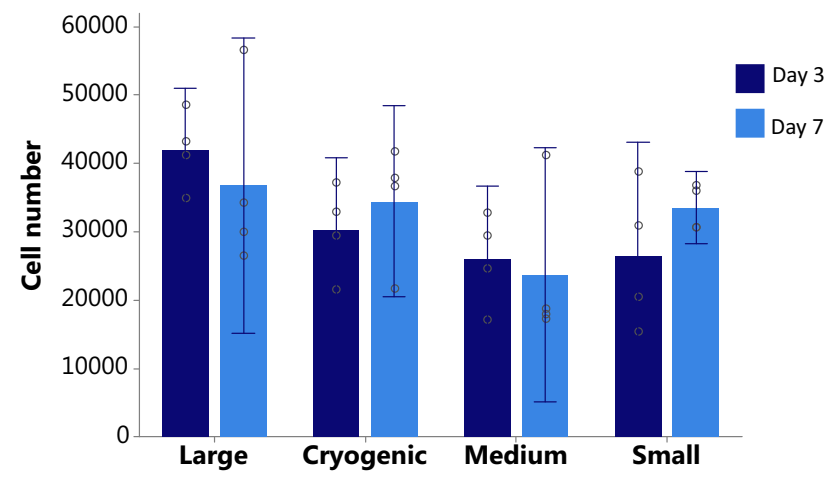

Fig. 3 Cell number estimated from a standard curve, analysed using a CellTitre blue ${ }^{\circledR}$ fluorescence assay. This demonstrates the ability of all scaffold architectures to support primary kidney cell life. No significant differences found in analysis using a one-way ANOVA $\mathrm{F}(7,24)=2.05, p=0.090$. Data presented as mean $\pm 95 \%$ confidence intervals, circles show individual data points

comes at the cost of mechanical strength; fibres had an UTS 5 times lower despite spinning under the same parameters, this follows a similar trend to previous works $[37,51]$. The variation seen in scaffold thickness may be influenced by a decrease in humidity due to the low temperature as humidity is known to effect the diameter of electrospun fibres [52], the low temperature of the mandrel may also reduce the ambient temperature increasing the viscosity of the polymer solution [53]. Interestingly, Young's modulus peaks in normally spun scaffolds at

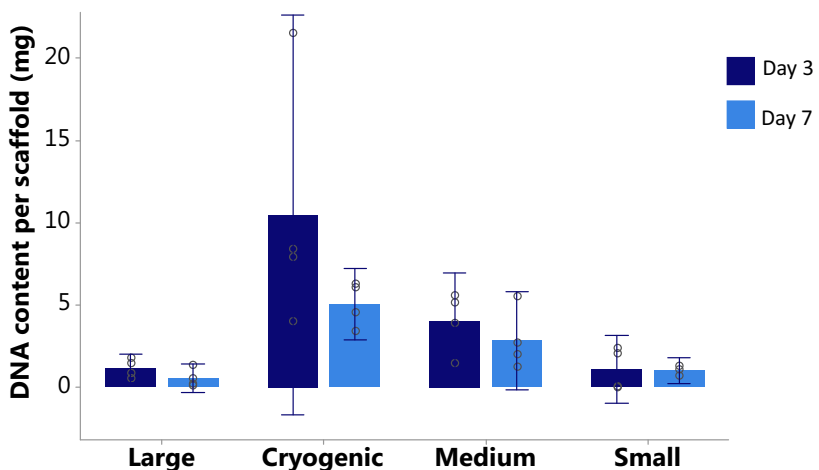

Fig. 4 DNA quantity per scaffold at 3 and 7 days, assessed by PicoGreen assay. This confirms the ability of all scaffold architectures to support primary kidney cell life. Analysis using a one-way ANOVA showed significant differences $\mathrm{F}(7,23)=4.79, p=0.002$, post hoc Tukey analysis shows that was in regards to cryogenic scaffolds. Data presented as mean $\pm 95 \%$ confidence intervals, circles denote individual data points

$2-3 \%$ strain but at $3-4 \%$ for cryogenically spun fibres this is probably due the nature of the scaffold and looser packing in cryogenic fibres allowing for more strain in the scaffold before all fibres are in tension. Cryogenic scaffold can be controlled further thought monitoring the humidity of spinning conditions [54].

There is great scope for the use of polymer scaffolds within kidney tissue engineering. Our work follows on from the limited published research into the use of kidney cells with electrospun scaffolds [13, 30, 55]. We have previously shown that electrospun PCL can be used to grow a kidney cells line, and highlighted the effects of morphological differences in scaffolds [39]. Here we have gone further, using RPK cells and demonstrating the survival of key cell types of this multi-cell population, Fig. 4. Although, our results regarding fibre diameter and its influence on cell behaviour are not conclusive, it has been shown to have major implication in previous studies [39, 56-58]. There is some disparity between our data for CellTitre blue and DNA quantification, this is possibly as a result of the much greater porosity gained from cryogenic electrospinning where unattached cells become trapped within the scaffold. It does however show that viable cells, shown through CellTitre blue, are surviving over time as DNA content remained constant.

An important factor to consider here is scaffold chemistry, we have demonstrated that PLA facilitates primary cell survival but it is not optimised for kidney cells. Survival on polymer scaffold could be vastly improved with optimisation through such techniques as microarray [59-61] allowing for analysis of cell interaction with many polymer types in a high-throughput manner. Other popular optimisation techniques include integrating ECM components with polymer scaffold to produce a hybrid deriving 
Fig. 5 Fluorescence images showing DAPI and IHC, used to show the presence of key functional marker of several cell types: A-D aquaporin-2, aquaporin-1 indicate the presence of tubular cells, von Willebrand factor indicates glomerular endothelial cells and synaptopodin indicated the glomerular epithelia, scale bar is $100 \mu \mathrm{m}$

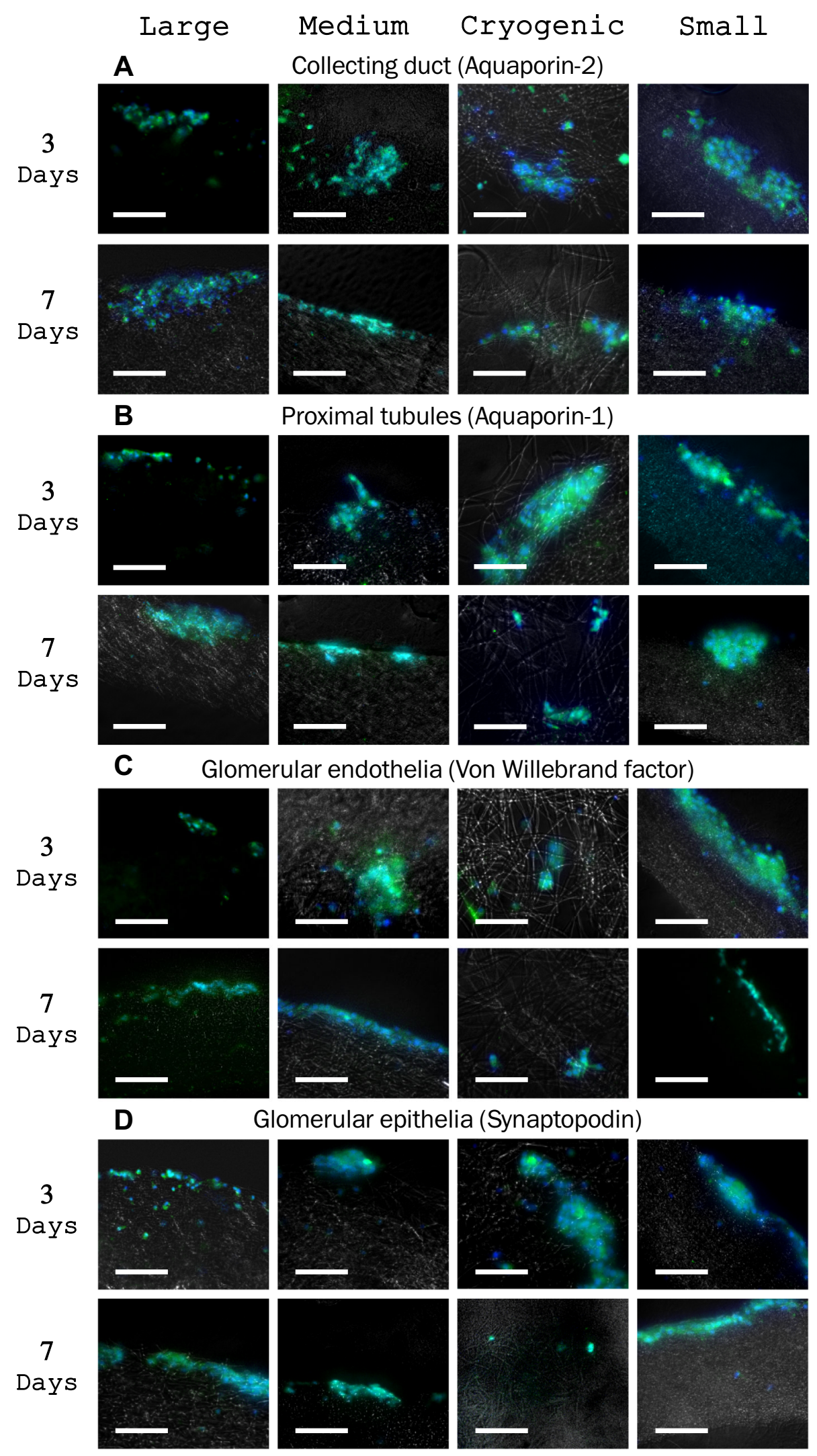


benefits from both, this method has shown to improve the mechanical properties of the scaffold whilst increasing cell interaction [31]. Further novel techniques have used a sacrificial cell layer to produce an ECM layer on top of the polymer scaffold before decellularisation, maintaining the initial mechanical characteristics [49]. Some of these methods may bring about a greater interaction between cells and scaffold and could provide more conclusive evidence on the type of architecture that is most favourable to kidney cells.

Fluorescence IHC images (Fig. 5) clearly shows the presence of key markers of essential kidney cells (Fig. 1). The marker which identified key cells were: aquaporin-1, aquaporin 2, Synaptopodin and von Willebrand factor, between them these highlight the cells which make up the proximal tubules, collecting duct, glomerular epithelia and glomerular endothelia, Fig. 1. The proximal tubules lead from the loop of Henle and are responsible for the reuptake of filtrate, they consist of epithelial cells with microvilli to increase surface area [7]. The collecting duct is the last stage of filtration where the filtrate is reabsorbed and collected. The glomerular epithelia are more commonly referred to as podocytes and form part of the glomerulus, playing a key role in blood filtration through slits which block the passage of larger molecules [62]. The glomerular endothelium are another key component of the glomerular characterised by fenestrations which are essential for filtration [63]. In order for any kidney tissue engineering scaffold intended to host a multi-cell population to be considered successful it is essential to show the survival of these key components; as can clearly be seen on our scaffolds cells were displaying initial integration with the 3D structure. The sectioned scaffolds did not fully integrate through the full depth in traditionally spun scaffolds, this is a common problem with electrospun fibres, reported in other works $[64,65]$. Pore size of the scaffold is the predominant factor which limits cell infiltration, naturally the larger the fibre the larger the pore size; methods such as cospinning of micro and nanofibres has been used to increase this pore space $[33,66]$, as well as using a sacrificial dissolvable polymer in a similar co-spinning manner [67]. Here we demonstrate the use of cryogenic spinning [51, 54], utilising ice crystals as a template the pore size is dramatically increased. Although our results on the most favourable morphology were inconclusive, we have demonstrated the greater cell integration cryogenic scaffold can bring, and have shown the potential of electrospun PLA as a scaffold for rat primary kidney cells and its capacity to maintain the multi-population of cells.

We did not see organisation of cells into kidney like structures and more research is needed over a longer time frame to assess for elements of self-organisation. The ability of embryonic and induced pluripotent stem cells to self-organise is well documented [6, 68], and these cells of greater physiological and clinical relevance are the next logical step for polymer scaffolds in kidney tissue engineering. Our view is that polymer scaffolds have the ability to act as a conveyor for kidney cells, allowing kidney cells to self-organise before implantation where a full organ can mature. We feel this is a reasonable alternative to the implantation of decellularised organs, and has previously been highlighted as a potential avenue [69].

We have demonstrated here the variation of architectures that can be created from a single polymer and solvent solution by electrospinning. This is just one polymer in many that could be used in kidney tissue engineering. Electrospun polymer scaffolds have the ability to create a range of different architectures and should be considered for further investigation in kidney tissue engineering due to their: ability to host a multi-population of cells, biocompatibility, reproducibility, good mechanical properties and 3D structure. This is a new non-woven path within kidney tissue engineering and one that should be explored further.

Acknowledgements This research is funded by an Engineering and Physical Sciences Research Council (EPSRC) Doctoral Training Partnership (DTP) Studentship and MRC computational and chemical biology of the stem cell niche Grant (CCBN) MR/L012766/1. We would like the thank Prof. Alistair Elfick for use of the lab facility, Stephen Mitchell at the BioSEM facility and Dr. David Kelly at the centre optical instrument laboratory (COIL) for use of their microscope.

\section{Compliance with ethical standards}

Conflict of interest The authors declare that they have no conflict of interest.

Ethical statement There are no animal experiments carried out for this article.

Open Access This article is distributed under the terms of the Creative Commons Attribution 4.0 International License (http://creative commons.org/licenses/by/4.0/), which permits unrestricted use, distribution, and reproduction in any medium, provided you give appropriate credit to the original author(s) and the source, provide a link to the Creative Commons license, and indicate if changes were made.

\section{References}

1. Webster AC, Nagler EV, Morton RL, Masson P. Chronic kidney disease. Lancet. 2017;389:1238-52.

2. Saran R, Li Y, Robinson B, Ayanian J, Balkrishnan R, BraggGresham J, et al. US renal data system 2014 annual data report: epidemiology of kidney disease in the United States. Am J Kidney Dis. 2015;66:A1-7, S1-305. https://doi.org/10.1053/j. ajkd.2015.05.001.

3. NHS Blood and Transplant. Organ donation and transplantation. Activity Report 2013-2014.

4. Abadie A, Gay S. The impact of presumed consent legislation on cadaveric organ donation: a cross-country study. J Health Econ. 2006;25:599-620. 
5. Humes HD, Buffington D, Westover AJ, Roy S, Fissell WH. The bioartificial kidney: current status and future promise. Pediatr Nephrol. 2014;29:343-51.

6. Davies JA, Chang C-H. Engineering kidneys from simple cell suspensions: an exercise in self-organization. Pediatr Nephrol. 2014;29:519-24.

7. Jang KJ, Mehr AP, Hamilton GA, McPartlin LA, Chung S, Suh $\mathrm{KY}$, et al. Human kidney proximal tubule-on-a-chip for drug transport and nephrotoxicity assessment. Integr Biol (Camb). 2013;5:1119-29.

8. Jang KJ, Suh KY. A multi-layer microfluidic device for efficient culture and analysis of renal tubular cells. Lab Chip. 2010; $10: 36-42$

9. Kim S, LesherPerez SC, Kim BC, Yamanishi C, Labuz JM, Leung B, et al. Pharmacokinetic profile that reduces nephrotoxicity of gentamicin in a perfused kidney-on-a-chip. Biofabrication. 2016;8:15021.

10. Zhou M, Zhang X, Wen $\mathrm{X}$, Wu T, Wang W, Yang $\mathrm{M}$, et al. Development of a functional glomerulus at the organ level on a chip to mimic hypertensive nephropathy. Sci Rep. 2016;6:31771.

11. Homan KA, Kolesky DB, Skylar-Scott MA, Herrmann J, Obuobi $\mathrm{H}$, Moisan A, et al. Bioprinting of 3D convoluted renal proximal tubules on perfusable chips. Sci Rep. 2016;6:34845.

12. Li M, Corbelli A, Watanabe S, Armelloni S, Ikehata M, Parazzi $\mathrm{V}$, et al. Three-dimensional podocyte-endothelial cell co-cultures: assembly, validation, and application to drug testing and intercellular signaling studies. Eur J Pharm Sci. 2016;86:1-12.

13. Slater SC, Beachley V, Hayes T, Zhang D, Welsh GI, Saleem $\mathrm{MA}$, et al. An in vitro model of the glomerular capillary wall using electrospun collagen nanofibres in a bioartificial composite basement membrane. PLoS One. 2011;6:e20802.

14. Xia Y, Sancho-Martinez I, Nivet E, Rodriguez Esteban C, Campistol JM, Izpisua Belmonte JC. The generation of kidney organoids by differentiation of human pluripotent cells to ureteric bud progenitor-like cells. Nat Protoc. 2014;9:2693-704.

15. Morizane R, Lam AQ, Freedman BS, Kishi S, Valerius MT, Bonventre JV. Nephron organoids derived from human pluripotent stem cells model kidney development and injury. Nat Biotechnol. 2015;33:1193-200.

16. Xinaris C, Benedetti V, Rizzo P, Abbate M, Corna D, Azzollini $\mathrm{N}$, et al. In vivo maturation of functional renal organoids formed from embryonic cell suspensions. J Am Soc Nephrol. 2012;23:1857-68.

17. Edmondson R, Broglie JJ, Adcock AF, Yang L. Three-dimensional cell culture systems and their applications in drug discovery and cell-based biosensors. Assay Drug Dev Technol. 2014;12:207-18.

18. Antoni D, Burckel H, Josset E, Noel G. Three-dimensional cell culture: a breakthrough in vivo. Int J Mol Sci. 2015;16:5517-27.

19. Pontes Soares C, Midlej V, de Oliveira ME, Benchimol M, Costa ML, Mermelstein C. 2D and 3D-organized cardiac cells shows differences in cellular morphology, adhesion junctions, presence of myofibrils and protein expression. PLoS One. 2012;7:e38147.

20. Bell CC, Hendriks DF, Moro SM, Ellis E, Walsh J, Renblom A, et al. Characterization of primary human hepatocyte spheroids as a model system for drug-induced liver injury, liver function and disease. Sci Rep. 2016;6:25187.

21. He M, Callanan A, Lagaras K, Steele JAM, Stevens MM. Optimization of SDS exposure on preservation of ECM characteristics in whole organ decellularization of rat kidneys. J Biomed Mater Res B Appl Biomater. 2017;105:1352-60.

22. Petrosyan A, Zanusso I, Lavarreda-Pearce M, Leslie S, Sedrakyan S, De Filippo RE, et al. Decellularized renal matrix and regenerative medicine of the kidney: a different point of view. Tissue Eng Part B Rev. 2016;22:183-92.
23. Bonandrini B, Figliuzzi M, Papadimou E, Morigi M, Perico N, Casiraghi $\mathrm{F}$, et al. Recellularization of well-preserved acellular kidney scaffold using embryonic stem cells. Tissue Eng Part A. 2014;20:1486-98.

24. Petrosyan A, Orlando G, Peloso A, Wang Z, Farney AC, Rogers $\mathrm{J}$, et al. Understanding the bioactivity of stem cells seeded on extracellular matrix scaffolds produced from discarded human kidneys : a critical step towards a new generation bio-artificial kidney. CellR4 Repair Replace Regen Reprogram. 2015;3:e1401.

25. Song JJ, Guyette JP, Gilpin SE, Gonzalez G, Vacanti JP, Ott HC. Regeneration and experimental orthotopic transplantation of a bioengineered kidney. Nat Med. 2013;19:646-51.

26. Fischer I, Westphal M, Rossbach B, Bethke N, Hariharan K, Ullah I, et al. Comparative characterization of decellularized renal scaffolds for tissue engineering. Biomed Mater. 2017; $12: 045005$

27. He M, Callanan A. Comparison of methods for whole-organ decellularization in tissue engineering of bioartificial organs. Tissue Eng Part B Rev. 2013;19:194-208.

28. Remuzzi A, Figliuzzi M, Bonandrini B, Silvani S, Azzollini N, Nossa R, et al. Experimental evaluation of kidney regeneration by organ scaffold recellularization. Sci Rep. 2017;7:43502.

29. Oo ZY, Kandasamy K, Tasnim F, Zink D. A novel design of bioartificial kidneys with improved cell performance and haemocompatibility. J Cell Mol Med. 2013;17:497-507.

30. Kim SS, Park HJ, Han J, Choi CY, Kim BS. Renal tissue reconstitution by the implantation of renal segments on biodegradable polymer scaffolds. Biotechnol Lett. 2003;25:1505-8

31. Lih E, Park KW, Chun SY, Kim H, Kwon TG, Joung YK, et al. Biomimetic porous PLGA scaffolds incorporating decellularized extracellular matrix for kidney tissue regeneration. ACS Appl Mater Interfaces. 2016;8:21145-54

32. Pham QP, Sharma U, Mikos AG. Electrospinning of polymeric nanofibers for tissue engineering applications: a review. Tissue Eng. 2006;12:1197-211.

33. Pham QP, Sharma U, Mikos AG. Electrospun poly(epsiloncaprolactone) microfiber and multilayer nanofiber/microfiber scaffolds: characterization of scaffolds and measurement of cellular infiltration. Biomacromolecules. 2006;7:2796-805.

34. Balguid A, Mol A, van Marion MH, Bank RA, Bouten CV, Baaijens FP. Tailoring fiber diameter in electrospun poly(epsiloncaprolactone) scaffolds for optimal cellular infiltration in cardiovascular tissue engineering. Tissue Eng Part A. 2009; 15:437-44

35. Wang J, Ye R, Wei Y, Wang H, Xu X, Zhang F, et al. The effects of electrospun TSF nanofiber diameter and alignment on neuronal differentiation of human embryonic stem cells. J Biomed Mater Res A. 2012;100:632-45.

36. Yan J, Qiang L, Gao Y, Cui X, Zhou H, Zhong S, et al. Effect of fiber alignment in electrospun scaffolds on keratocytes and corneal epithelial cells behavior. J Biomed Mater Res A. 2012;100:527-35

37. Leong MF, Rasheed MZ, Lim TC, Chian KS. In vitro cell infiltration and in vivo cell infiltration and vascularization in a fibrous, highly porous poly(D,L-lactide) scaffold fabricated by cryogenic electrospinning technique. J Biomed Mater Res A. 2009;91:231-40.

38. McHugh KJ, Tao SL, Saint-Geniez M. A novel porous scaffold fabrication technique for epithelial and endothelial tissue engineering. J Mater Sci Mater Med. 2013;24:1659-70.

39. Burton TP, Corcoran A, Callanan A. The effect of electrospun polycaprolactone scaffold morphology on human kidney epithelial cells. Biomed Mater. 2017;13:015006. 
40. Callanan A, Davis NF, McGloughlin TM, Walsh MT. The effects of stent interaction on porcine urinary bladder matrix employed as stent-graft materials. J Biomech. 2014;47:1885-93.

41. Joraku A, Stern KA, Atala A, Yoo JJ. In vitro generation of threedimensional renal structures. Methods. 2009;47:129-33.

42. Takasato M, Er PX, Becroft M, Vanslambrouck JM, Stanley EG, Elefanty AG, et al. Directing human embryonic stem cell differentiation towards a renal lineage generates a self-organizing kidney. Nat Cell Biol. 2014;16:118-26

43. Takasato M, Er PX, Chiu HS, Maier B, Baillie GJ, Ferguson C, et al. Kidney organoids from human iPS cells contain multiple lineages and model human nephrogenesis. Nature. 2015;526: 564-8

44. Shamir ER, Ewald AJ. Three-dimensional organotypic culture: experimental models of mammalian biology and disease. Nat Rev Mol Cell Biol. 2014;15:647-64.

45. Poornejad N, Buckmiller E, Schaumann L, Wang H, Wisco J, Roeder B, et al. Re-epithelialization of whole porcine kidneys with renal epithelial cells. J Tissue Eng. 2017;8:204173 1417718809.

46. Poornejad N, Nielsen JJ, Morris RJ, Gassman JR, Reynolds PR, Roeder BL, et al. Comparison of four decontamination treatments on porcine renal decellularized extracellular matrix structure, composition, and support of renal tubular epithelium cells. J Biomater Appl. 2016;30:1154-67.

47. Peloso A, Tamburrini R, Edgar L, Wilm B, Katari R, Perin L, et al. Extracellular matrix scaffolds as a platform for kidney regeneration. Eur J Pharmacol. 2016;790:21-7

48. O'Brien FJ. Biomaterials and scaffolds for tissue engineering. Mater Today (Kidlington). 2011;14:88-95.

49. Grant R, Hay DC, Callanan A. A drug-induced hybrid electrospun poly-capro-lactone: cell-derived extracellular matrix scaffold for liver tissue engineering. Tissue Eng Part A. 2017;23:650-62.

50. Behrens AM, Kim J, Hotaling N, Seppala JE, Kofinas P, Tutak W. Rapid fabrication of poly(D,L-lactide) nanofiber scaffolds with tunable degradation for tissue engineering applications by air-brushing. Biomed Mater. 2016;11:35001.

51. Simonet M, Schneider OD, Neuenschwander P, Stark WJ. Ultraporous 3D polymer meshes by low-temperature electrospinning: use of ice crystals as a removable void template. Polym Eng Sci. 2007;47:2020-6.

52. De Vrieze S, Van Camp T, Nelvig A, Hagström B, Westbroek P, De Clerck K. The effect of temperature and humidity on electrospinning. J Mater Sci. 2009;44:1357-62

53. Casasola R, Thomas NL, Trybala A, Georgiadou S. Electrospun poly lactic acid (PLA) fibres: effect of different solvent systems on fibre morphology and diameter. Polymer. 2014;55:4728-37.

54. Leong MF, Chan WY, Chian KS. Cryogenic electrospinning: proposed mechanism, process parameters and its use in engineering of bilayered tissue structures. Nanomedicine (Lond). 2013;8:555-66.

55. Burton TP, Callanan A. Engineering the kidney: the effects of scaffold architecture. Eur Cells Mater Suppl 4. 2016;32:13.

56. Sultana N, Wang M. PHBV/PLLA-based composite scaffolds fabricated using an emulsion freezing/freeze-drying technique for bone tissue engineering: surface modification and in vitro biological evaluation. Biofabrication. 2012;4:015003.

57. Daud MF, Pawar KC, Claeyssens F, Ryan AJ, Haycock JW. An aligned 3D neuronal-glial co-culture model for peripheral nerve studies. Biomaterials. 2012;33:5901-13.

58. Hodgkinson T, Yuan XF, Bayat A. Electrospun silk fibroin fiber diameter influences in vitro dermal fibroblast behavior and promotes healing of ex vivo wound models. J Tissue Eng. 2014;5:1-13.

59. Khan F, Tare RS, Kanczler JM, Oreffo ROC, Bradley M. Strategies for cell manipulation and skeletal tissue engineering using high-throughput polymer blend formulation and microarray techniques. Biomaterials. 2010;31:2216-28.

60. Duffy CRE, Zhang R, How SE, Lilienkampf A, Tourniaire G, Hu $\mathrm{W}$, et al. A high-throughput polymer microarray approach for identifying defined substrates for mesenchymal stem cells. Biomater Sci. 2014;2:1683-92.

61. Hook AL, Chang CY, Yang J, Scurr DJ, Langer R, Anderson DG, et al. Polymer microarrays for high throughput discovery of biomaterials. J Vis Exp. 2012;59:e3636.

62. Ni L, Saleem M, Mathieson PW. Podocyte culture: tricks of the trade. Nephrology (Carlton). 2012;17:525-31.

63. Satchell S. The role of the glomerular endothelium in albumin handling. Nat Rev Nephrol. 2013;9:717-25.

64. McCullen SD, Autefage H, Callanan A, Gentleman E, Stevens MM. Anisotropic fibrous scaffolds for articular cartilage regeneration. Tissue Eng Part A. 2012;18:2073-83.

65. Accardi MA, McCullen SD, Callanan A, Chung S, Cann PM, Stevens MM, et al. Effects of fiber orientation on the frictional properties and damage of regenerative articular cartilage surfaces. Tissue Eng Part A. 2013;19:2300-10.

66. Soliman S, Pagliari S, Rinaldi A, Forte G, Fiaccavento R, Pagliari $\mathrm{F}$, et al. Multiscale three-dimensional scaffolds for soft tissue engineering via multimodal electrospinning. Acta Biomater. 2010;6:1227-37.

67. Phipps MC, Clem WC, Grunda JM, Clines GA, Bellis SL. Increasing the pore sizes of bone-mimetic electrospun scaffolds comprised of polycaprolactone, collagen I and hydroxyapatite to enhance cell infiltration. Biomaterials. 2012;33:524-34.

68. Little MH. Generating kidney tissue from pluripotent stem cells. Cell Death Discov. 2016;2:16053.

69. Kim S, Fissell WH, Humes HD, Roy S. Current strategies and challenges in engineering a bioartificial kidney. Front Biosci (Elite Ed). 2015;7:215-28. 